\title{
Pre-counterfactuals and Anticipated Emotions: Factors Affecting the First Bid in Name-your-own-price Auctions
}

\author{
Kuo-Chuan Chu ${ }^{1} \&$ Kyoung-Nan Kwon ${ }^{2}$ \\ ${ }^{1}$ Department of Advertising, Public Relations, and Retailing, Michigan State University, East Lansing, USA \\ ${ }^{2}$ College of Business Administration, Ajou University, Suwon, Republic of Korea \\ Correspondence: Kyoung-Nan Kwon, San 5 Wonchun-Dong, Youngton-Gu, Ajou University, Suwon, Republic \\ of Korea. Tel: 82-31-219-3629. E-mail: kwonkn@ajou.ac.kr
}

Received: October 9, 2013 Accepted: November 15, 2013 Online Published: January 16, 2014

doi:10.5539/res.v6n1p34 URL: http://dx.doi.org/10.5539/res.v6n1p34

\begin{abstract}
This research examines the effects of pre-counterfactual thinking and anticipated emotions on the amount of the first bid placed in Name-Your-Own-Price auctions. The results of Study 1 indicate that upward counterfactuals are elicited more than downward counterfactuals in response to both accepted and rejected bids. Study 2 investigates the effect of imagination of upward counterfactual thinking on the first bid. The results indicate that upward pre-counterfactual thinking about an accepted bid results in anticipated regret, which increases the amount of the first bid; however, the amount is not influenced by anticipated disappointment resulting from pre-counterfactual thinking of a rejected bid.
\end{abstract}

Keywords: auction, counterfactual thinking, anticipated emotions, regret, disappointment

\section{Introduction}

Interactive pricing mechanisms, in which both buyers and sellers actively participate in the price-generating process, have become increasingly popular in online markets. Auctions are the most commonly known form of interactive pricing mechanisms. Jones et al. (2000) distinguished seller auctions from buyer auctions. In a seller's auction, the buyers compete against each other for the bidding item from a seller and the winner is the one with the highest bid. On the other hand, in a buyer's auction, the buyer initiates an auction by requesting to purchase an item.

One type of the buyer's auction is the Name-Your-Own-Price (NYOP) auction. Introduced by Priceline.com, this new and interesting online transaction mode of NYOP has become a popular bidding system that provides savings to consumers and additional revenues to suppliers (Jones et al., 2000). Different from buyers in seller's auctions, buyers in NYOP auctions bid for a product against an unrevealed threshold price determined by the seller. Specifically, NYOP is a reverse auction that allows sellers to compete for the bid submitted by a buyer, while in traditional auctions buyers compete for a product by increasing its start price set by the seller (e.g., eBay.com) (Tassabehji et al., 2006). The most appealing aspect of the NYOP auction is that buyers, rather than the seller, decide the price for a product or service (Chernev, 2003).

The bidding process in an NYOP auction, for a hotel room for example, begins by the bidder choosing desired attributes (e.g., the star level or the location of a hotel) and then submitting a price without knowing the name of the hotel that may be selected. Upon receiving the bid, the system takes a few minutes to search its price database, which contains the lowest acceptable prices by various hotel partners. If the bid is higher than the lowest price acceptable in the system, it will be accepted immediately; otherwise, it will be rejected. Once the bid is accepted, it is neither cancellable nor refundable. When the bid is rejected, the bidder can bid again either by changing the desired characteristics or after waiting for a specific period of time. Thus, the buyer does not determine the winning bid but the system selects a seller whose offer meets the buyer's criteria for a bid. In addition, the buyer has no control over seller competition (Jones et al., 2000).

In most consumer purchases, quality evaluation involves a certain degree of uncertainty because purchase decisions are made before experiencing full usage. In more traditional auction markets, physical inspection of a product and the ability to specify the exact nature of an acceptable product or service might reduce some of the quality uncertainty. However, bidders in NYOP auctions deal with more uncertainty, compared to buyers in 
conventional retail purchases, since bidders do not have complete information regarding many attributes of the products or services for which they submit bids (Shapiro \& Zillante, 2009). For example, when a bid is placed for a hotel, the bidder can select a star level and an area of location but does not have detailed information on other aspects such as the hotel name, room type, and the exact location.

The buyer's inability to know in advance the exact nature of the product or service in NYOP auctions creates a high level of uncertainty. The uncertainty in NYOP auctions stems from not only the bidding outcome of whether the bid is accepted, but more importantly, the very nature of the bidding system in which bidders make payments without knowing exactly what products or services they are purchasing. Thus, bidders have to predetermine the price they are willing to pay for a product or service with only certain attributes revealed, which is perceived as highly risky behavior (Vishwanath, 2003). Given that the buyers are uncertain about a bidding item's value, how do bidders manage such quality uncertainty and decide their bid amount? The high uncertainty in NYOP bidding may result in various coping behaviors, and we believe counterfactual thinking, which will be investigated in this study, is one of them.

Mental simulation such as counterfactual thinking is a way for people to deal with the uncertainty of consequences, which can ease the decision-making difficulties associated with the uncertainty (Kahneman \& Tversky, 1982). Counterfactual thinking, which is defined as thoughts that occur when people imagine alternatives different from what has occurred in the past, is a cognitive rule of mental simulation (Roese \& Hur, 1997). Previous studies suggest that people may simulate different possible outcomes before making a decision in order to avoid undesired outcomes (Hetts et al., 2000; McConnell et al., 2000). It is also suggested that counterfactual thoughts generate affective reactions, and the critical importance of counterfactuals on decision making is increasingly discussed in the literature (Kahneman \& Miller, 1986; Roese, 1994). The emotions anticipated as a result of counterfactual thinking can affect decisions involving uncertain choices (Zeelenberg, 1999). It is possible that counterfactual thoughts may occur to bidders in deciding their first bids due to uncertainties. Thus, two experimental studies conducted in the current research examine whether the anticipation of counterfactual thinking and the consequent emotions generated from possible bidding outcomes (e.g., imagination of an accepted bid and a rejected bid) influence the decision of the first bidding price.

\section{Study 1: Counterfactual Thinking}

When bids are rejected in NYOP auctions, counterfactual thoughts for better possible scenarios may occur (e.g., I wish my bid had been accepted) (Roese \& Hur, 1997; Roese \& Olson, 1997; Sanna \& Turley, 1996). Previous studies suggest that counterfactual thoughts also occur when the first offer is accepted because the bidder may think about how he or she could have done better (e.g., If I had bid lower, I could have gotten a better deal) (Galinsky et al., 2002; Roese \& Hur, 1997; Sanna \& Turley, 1996). These counterfactuals can influence future behaviors (e.g., bidding lower next time) (Boninger et al., 1994; Roese, 1994).

There are two different types of counterfactual thinking: upward vs. downward counterfactual thinking (Sanna, 1996). In upward counterfactual thinking, an alternative that is better than what actually happened is imagined; in downward counterfactual thinking, an alternative that is worse than the actual outcome is imagined. Since bidding decisions involve a tradeoff between the probability of winning and the amount of the bid, both upward and downward counterfactual thinking can possibly occur even for the same bidding result (i.e., a rejected bid or an accepted bid). The type of counterfactual thought that occurs is dependent on whether the focus of thinking is rejection versus acceptance or the amount of the bid. That is, when a bid is accepted, the bidder may think "I should have bid lower and it would still have been accepted" (upward), or "if I had bid lower, the bid might have been rejected" (downward). On the other hand, when the bid is rejected, the bidder holding an upward counterfactual thought may imagine an acceptance (e.g., "I wish my bid had been accepted") or imagine overbidding (e.g., "If I had bid higher, I might have overbid") as possible downward counterfactual thinking.

In general, people are more concerned with how things could have been better rather than worse than the reality (Markman et al., 1993). Past research suggests that when people respond to a negative outcome, counterfactual thinking is more likely to be upward than downward (McConnell et al., 2000; Roese \& Olson, 1997). Thus, we expect that upward counterfactual thinking occurs more often than downward counterfactual thinking in a bidder when the first bid is rejected. That is, when the first bid is rejected, bidders may mentally simulate a potentially better outcome (an accepted bid) rather than a possible worse outcome (overbidding), compared to the actual outcome (the rejected bid).

Although previous research addresses counterfactuals in relation only to negative outcomes, we expect the prominent presence of upward counterfactuals not only for rejected bids but also for accepted bids. That is, when the first bid is accepted, an upward counterfactual is more likely to be generated than a downward counterfactual 
thought: bidders will think of a potential better outcome (e.g., an accepted bid at lower bidding price) rather than a possible worse outcome (a rejected bid). One may argue whether counterfactual thoughts even occur for accepted bids, positive outcomes. In NYOP auctions, bidders tend to place relatively low first bids without much expectation that they will be accepted because they can bid again immediately after rejections. Thus, if an immediately accepted bid is an unexpected outcome, such an unexpected outcome is likely to evoke a counterfactual thought (Galinsky et al., 2002; Kahneman \& Miller, 1986; Roese \& Hur, 1997; Sanna \& Turley, 1996). Once a bid is accepted, we believe it is natural that attention shifts from the winning of the bid to the amount of the bid to a certain degree (e.g., "I could have bid lower"). Thus, we propose that there is a greater occurrence of upward counterfactual thinking than downward thinking for both accepted and reject bids.

H1: Bidders are more likely to engage in upward counterfactual thinking than in downward counterfactual thinking when their first bid is rejected.

$\mathrm{H} 2$ : Bidders are more likely to engage in upward counterfactual thinking than in downward counterfactual thinking when their first bid is accepted.

Further, we investigate whether the extent of upward counterfactual thinking is more prominent when a bid is rejected or when it is accepted, and we speculate three different ways in this regard. First, risk literature suggests that, due to the tendency toward loss aversion, consumers behave more sensitively when they face losses than gains (Kahneman et al., 1991). Gleicher et al. (1995) and Roese \& Olson (1997) suggest that upward counterfactual thinking occurs more often when the outcome is negative than when the outcome is positive. According to the suggestions in the literature, we should expect more upward counterfactual thinking generated for rejected bids than for accepted bids.

On the other hand, the opposite result is also possible considering the nature of NYOP auctions. When a bid is rejected, the bidder is offered the opportunity to bid again immediately, whereas it is impossible to cancel or refund an accepted bid. Because second chances are offered after rejected bids, rejections are less likely to generate upward counterfactual thoughts compared to accepted bids. In addition, Galinsky et al. (2002) found that compared to a delayed acceptance or negotiated acceptance of one's first offer, an immediate acceptance increases upward counterfactual activation. The reason why upward counterfactual thoughts are more likely to be activated when the first offer is immediately accepted is that an immediate acceptance is perceived as an "abnormal" cause (i.e., one that is exceptional rather than routine) and this exceptionality increases the occurrence of upward counterfactual thoughts (Galinsky et al., 2002; Kahneman \& Miller, 1986).

Another possibility is that there is no difference between rejected and accepted bids. As mentioned earlier, when comparing a rejected bid to an accepted bid, judging which one is a better or more positive outcome is complicated due to the tradeoff nature of bidding decisions. For example, a rejected bid may not be an absolutely negative outcome. A bidder may be immediately disappointed when his bid is rejected. On the other hand, when the focus of his thinking shifts from the rejection to the bidding amount, he may also think it was a good thing because the rejection meant he did not overbid, and he would have overbid if he had bid higher. Thus, it may be reasonable to expect no difference in upward counterfactual thinking between rejected bids and accepted bids because rejections and acceptances can be considered as either gains or losses depending on the bidder's perspective. In sum, because of the three different possibilities discussed above, we propose a research question rather than a hypothesis.

RQ: Do bidders engage in upward counterfactual thinking more or less when their first bid is rejected than when their first bid is accepted?

\subsection{Method}

A total of 125 undergraduates at a U.S. Midwestern university were recruited to participate in our study. Participants were provided with a questionnaire containing a scenario. They were asked to imagine that they would bid for travel to a southern city that they had never been to before and would bid for a 3-star hotel in that area. A median retail price of a 3-star hotel -US\$137 in that area-was provided as a reference price. Participants were then asked to write the price they were willing to pay. After writing down their first bid, participants were assigned randomly to one of the two conditions: accepted bids and rejected bids.

Fifty-nine participants were assigned to the accepted-bid condition and 66 participants to the rejected-bid condition. In order to examine whether bidders experienced more upward or downward counterfactual thinking in the two conditions, we asked participants to indicate the type of counterfactual thinking, either upward or downward, that came first to their minds. In the condition where the first bid was accepted, the participants had to choose either "If I had bid lower, I might have saved more" (upward), or "If I had bid lower, my bid might 
have been rejected" (downward). In the condition where the first bid was rejected, the participants had to choose either "I wish my bid had been accepted" (upward), or "If I had bid higher, I might have overbid" (downward).

\subsection{Results}

Responses from 125 participants including 43 males and 82 females were analyzed. Only 22 participants claimed that they had bidding experience in NYOP auctions. More than half of the participants did not have prior bidding experience. All participants were provided with information on NYOP auctions and qualification checks for their understanding were conducted.

\subsubsection{Qualification Checks}

All participants were provided general information on the NYOP auction and were asked to answer four true/false questions. An example of these questions is "When my bid is REJECTED, I can place exactly the same bid again immediately." These qualification checks were conducted in order to ensure that participants' responses were based on correct understanding of the bidding system. After excluding responses from 8 participants who did not complete the questionnaire and 25 participants who did not answer all the qualification check questions correctly, 92 valid responses were analyzed.

\subsubsection{Hypothesis Testing}

The number of upward and downward counterfactual thoughts that was indicated by participants was compared in order to test $\mathrm{H} 1$ and $\mathrm{H} 2$, and both hypotheses were supported. In the rejected-bid condition, upward counterfactual thinking was chosen more $(71 \%)$ than downward counterfactual thinking $(29 \%), \chi^{2}(1, N=48)=$ $8.333, p=.004$. A similar finding was revealed for the accepted-bid condition. Upward counterfactual thinking was generated more $(66 \%)$ than downward counterfactual thinking $(34 \%), \chi^{2}(1, N=44)=4.455, p=.035$. These findings support our hypotheses that upward counterfactual thinking is evoked more than downward counterfactual thinking regardless of whether the bid is accepted or rejected. In order to investigate whether upward counterfactual thoughts are generated more in accepted bids or rejected bids, we compared the frequency of bidders who engaged in upward counterfactual thoughts in two different bidding scenarios. The results indicate that there was no significant difference in upward counterfactual thinking between the accepted-bid and the rejected-bid conditions $(p=.529)$.

\subsection{Discussion}

The findings of Study 1 indicate that the counterfactual thoughts occurring after both accepted and rejected bids are upward in direction, which is consistent with the findings of previous studies (Galinsky et al., 2002; Markman et al., 1993). The occurrence of upward counterfactuals appears to be equally significant whether bids are accepted or rejected. This finding contradicts the general notion of risk-aversion (Kahneman \& Tversky, 1979) and recent studies (McConnell et al., 2000; Roese \& Olson, 1997) that suggest more prominent upward counterfactuals to negative outcomes. We attribute this finding to the tradeoff nature of bidding decisions (i.e., the probability of winning and the amount of the bid to place) in which neither rejection nor acceptance can be perceived as an absolute loss or gain. It is interesting to note that the rejected bids that have a chance to bid again generate counterfactual thoughts as much as accepted bids.

One significant issue in counterfactual thinking is that upward counterfactual thought often results in a high level of negative emotions because such thoughts focus on imagined outcomes that are better than the outcome actually obtained (Gleicher et al., 1990; McConnell et al., 2000; Roese, 1997). Negative emotions resulting from upward counterfactual thoughts can affect decision making in the future (Roese, 1994). For example, when the first bid is accepted, the negative emotions from a possible upward counterfactual (e.g., "If I had bid lower, I might have saved more") can decrease the amount of a bid placed in the future. In Study 2, we investigate whether bidders anticipate the negative emotions that are generated by upward counterfactuals of different bidding outcomes and if anticipated emotions affect their current bidding decisions. Additionally, we will test the hypotheses of Study 1 again in Study 2 for consistent findings.

\section{Study 2: Pre-counterfactual Thinking and Anticipated Emotions}

Study 2 is built on the findings of Study 1 and investigates how the anticipation of negative emotions generated by upward pre-counterfactuals affects bidding decisions. Counterfactual thoughts are generated in response not only to the events that have occurred but also to imagined outcomes (Gleicher et al., 1995). The latter thoughts are called pre-counterfactuals. Pre-counterfactuals are a special type of counterfactual thoughts in which a mental simulation of an anticipated event is activated before a decision is made (Gleicher et al., 1995; McConnell et al., 2000; Sanna, 1996). The influence of counterfactual thinking on decision making in NYOP auctions may be more critical in relation to the anticipated bidding outcome than the actual outcome, since the 
decision context is highly uncertain. The activation of pre-counterfactuals can ease decision difficulties (Kahneman \& Tversky, 1982).

Bidders possibly have expectations of how likely it is that their bid will be accepted, which can be their general expectation based on their market knowledge or based on the information provided by the business site (e.g., the average market price). Thus, bidders may imagine their bid is likely to be rejected or accepted, and the thought generated due to this anticipation is a critical factor that affects the actual bidding decision, especially the decision for the amount of the first bid. In study 2, we examine how the amount of the first bid is influenced by the negative emotions elicited from upward pre-counterfactual thoughts in the imagined accepted-bid and rejected-bid conditions.

Upward pre-counterfactual thinking, which can potentially worsen a person's affective experience, may affect the course of action prior to a decision (Gleicher et al., 1995; Hetts et al., 2000). That is, a person conceives an upward counterfactual thought with regard to the outcome he anticipates and takes action to avoid the negative emotions generated by the counterfactuals (Miller \& Taylor, 1995). For example, a bidder may imagine that her first bid is accepted before placing a bid and develop an upward pre-counterfactual: "It is possible that I might not have bid as low as possible. I could have bid even lower and would have saved more money and my bid would still have been accepted." In this example, the imagined overpayment might cause negative feelings. By the same token, when the bidder imagines that her first bid is rejected, an upward pre-counterfactual, "I wish my bid had been accepted," might also cause a negative feeling such as disappointment. In order to avoid negative emotions, bidders might take different actions such as bidding lower for an imagined accepted bid and bidding higher for an imagined rejected bid.

Previous studies indicate that upward counterfactual thinking leads to negative emotions (Boninger et al., 1994; Gleicher et al., 1990; Kahneman \& Miller, 1986; Roese, 1994). In particular, recent studies have found that regret and disappointment are two critical, different types of negative emotions in response to counterfactual thoughts, and they are directly related to decision making (Inman et al., 1997; Marcatto \& Ferrante, 2008; Zeelenberg et al., 1998b; Zeelenberg \& Pieters, 1999; Zeelenberg et al., 2000). Thus, the current paper investigates if upward counterfactuals in response to imagined accepted and rejected bids result in regret and disappointment differently and how these two emotions influence bidding decisions.

In our daily life, we live through various negative experiences or incidents; some of them result from our own behaviors, while others may be attributed to situations that we have no control over. Zeelenberg et al. (1998b) distinguished a behavior-focused counterfactual from a situation-focused counterfactual. A behavior-focused counterfactual is a thought that a certain event could have turned out differently based on the belief that the cause of the event was a person's own behavior (e.g., "If I had gotten up early, I might have caught the train"). However, in a situation-focused counterfactual, the cause of the outcome is not believed to be under one's control (e.g., "I wish my flight had not been delayed").

People feel regret when the imagined alternative is better than the actual outcome. The emotion of regret is a feeling of responsibility for not making a right choice, which includes a sense of self-blame with respect to the cause (Zeelenberg et al., 2000). On the other hand, disappointment occurs when there is a discrepancy between the actual and expected performance (i.e., disconfirmed expectation), and the decision-maker might not necessarily blame this on his or her own behavior because the result is beyond the person's control (Bell, 1985; Zeelenberg et al., 2000). According to Zeelenburg et al. (1998b), behavior-focused counterfactuals result in regret, which is a cognitive emotion that is driven by comparisons between the actual outcome and a better outcome that might have been obtained. On the other hand, situation-focused counterfactuals result in disappointment, which is a less cognitive emotional response to unexpected events. According to Marcatto and Ferrante (2008), the differences between regret and disappointment are in the type of attribution (internal versus external attribution) and the locus of control (choice- versus event-focused counterfactuals). The emotion of regret arises due to internal attribution and choice-focused counterfactuals, whereas disappointment is related to external attribution and event-focused counterfactuals.

Our findings in Study 1 suggest that both accepted bids and rejected bids result in upward, rather than downward, counterfactual thinking. We question whether the upward counterfactual thoughts are behavior-focused or situation-focused. In NYOP auctions, the amount of a bid and the bidding result (rejection or acceptance) are highly correlated and are decided by different parties. The amount of a bid is decided by the bidder's own action; thus, counterfactuals related to the bid amount are behavior-focused. On the other hand, the bidder will be told whether their bid is rejected or accepted; thus, counterfactual thoughts related to the mere fact of losing or winning are considered situation-focused. Therefore, the upward counterfactual thought of an accepted bid that 
we investigate in this study ("If I had bid lower, I might have saved more") is behavior-focused because the amount of the bid is the bidder's decision and it is under the bidder's personal control. Alternatively, the upward counterfactual thought of a rejected bid ("I wish my bid had been accepted") is a situation-focused counterfactual because whether the bid is accepted or rejected is determined by the bidding system, which is beyond the bidder's personal control.

Therefore, we hypothesize that bidders will experience anticipated regret more than anticipated disappointment when they engage in the upward pre-counterfactual relative to an expected accepted bid and vice versa when they engage in the upward pre-counterfactual relative to an expected rejected bid.

H3: Upward pre-counterfactual thinking regarding an imagined accepted bid will result in anticipated regret more than anticipated disappointment.

H4: Upward pre-counterfactual thinking regarding an imagined rejected bid will result in anticipated disappointment more than anticipated regret.

Taylor and Schneider (1989) argue that imagination of a scenario elicits emotional reactions, and the importance of event simulation is in the regulation of emotional states. The literature on emotion regulation suggests that "the tendencies to avoid negative emotions like regret and to strive for positive emotions like rejoicing are important determinants of human decision making" (Zeelenberg, 1999, p. 95). The anticipation of future emotions may motivate people to think more elaborately and consequently influence their current decisions with uncertain outcomes (Baumgartner et al., 2008; Miller \& Taylor, 1995; Zeelenberg, 1999). If a bidder experiences negative anticipated emotions due to upward pre-counterfactual thinking, he will engage in a specific action to regulate the emotions. Particularly, we expect that motivation to regulate the negative anticipated emotions will affect how much to bid. That is, in order to avoid the anticipated regret of not bidding lower in response to the thought of an imagined accepted bid, the bidder will bid lower than those who do not experience the emotion. On the other hand, in order to regulate the anticipated disappointment about an imagined rejected bid, the bidder will bid higher.

H5: There is a negative relationship between the amount of the first bid and the anticipated regret generated from the upward pre-counterfactual thinking about an imagined accepted bid.

H6: There is a positive relationship between the amount of the first bid and the anticipated disappointment generated from upward pre-counterfactual thinking about an imagined rejected bid.

One distinctive characteristic of NYOP bidding is that bidders have a second chance to bid when their first bids are rejected, but the bidding results are irrevocable when their first bids are accepted. Because of this difference in the chance to bid again, we expect that the influence of anticipated emotion is more significant for an accepted bid than for a rejected bid. The literature on emotion also suggests that people are more likely to develop a desire to undo or correct the action taken previously when they had control over the decision made than when the outcome was situation-driven (Markman et al., 1995; Zeelenberg et al., 1998a). As discussed earlier, regret is distinguished from disappointment by the externality in locus of control. We propose that anticipated regret affects the amount of the first bid to a greater degree than does anticipated disappointment.

H7: The influence of anticipated regret on the amount of the first bid (H5) will be greater than the influence of anticipated disappointment (H6).

\subsection{Method}

\subsubsection{Participants and Procedure}

The participants included 203 undergraduate students at a U.S. Midwestern university. The overall procedure was similar to Study 1. We manipulated the hypothetical upward pre-counterfactual into two conditions: an imagined accepted bid and an imagined rejected bid. Through random assignment, 104 participants were asked to read the imagined accepted-bid scenario, while 99 participants were asked to read the imagined rejected-bid scenario.

For the upward pre-counterfactual thinking regarding an accepted bid, participants were asked to imagine the following scenario:

After I submit a bid, only a few minutes later, the system shows me that my bid is accepted. I can neither cancel it nor bid again. I think if I had bid lower, I might have saved more.

For the upward pre-counterfactual thinking regarding a rejected bid, the participants were asked to imagine the following scenario: 
After I submit a bid, only a few minutes later, the system shows me that my bid is rejected.

I wish my bid had been accepted but I can bid again.

After reading the scenario, the participants were asked to indicate the degree of their regret and disappointment. Finally, the participants were asked to write down the price they were willing to pay for a 3-star hotel in their first bids.

\subsubsection{Measures}

Although regret and disappointment are conceptually distinct (Inman et al., 1997; Zeelenberg et al., 1998b; Zeelenberg \& Pieters, 1999; Zeelenberg et al., 2000), there are only a few measures available that properly reflect the conceptual differences. The traditional regret and disappointment measure asks simply "how much regret do you feel" and "how much disappointment do you feel" (van Dijk \& Zeelenberg, 2005; Zeelenberg et al., 1998a). We used the two 7-point scale items, anchored from "not at all" (1) to "very much" (7). Recently, a new measure of regret and disappointment was introduced that distinguishes regret from disappointment on the basis of different cognitive antecedents of the emotions (Marcatto \& Ferrante, 2008). Among the seven original items, we used four relevant items pertaining to the main cognitive antecedents of regret and disappointment (internal/external attribution and internal/external responsibility) using a 7-point Likert scale anchored from "strongly disagree" (1) to "strongly agree" (7). Thus, a total of six items were used to measure anticipated regret and anticipated disappointment in this study. The reliability was .66 for the anticipated regret items and .63 for the anticipated disappointment items. These reliability scores are lower than the traditional rule of thumb of .7; however, Cortina (1993) suggested that Cronbach's alpha scores of .6 or higher are acceptable for measures with fewer items (six or less).

The first bidding price was measured by an open-ended question: "I will submit a bid at $\$$

\subsection{Results}

For Study 2, 75 male and 128 female participants were recruited. As in Study 1, a series of questions was asked to test participants' understanding of the NYOP information provided. After excluding responses from participants who did not answer all NYOP questions correctly and those who did not complete the questionnaires, 173 responses were analyzed.

$\mathrm{H} 3$ and $\mathrm{H} 4$ were tested by comparing the means of anticipated regret and anticipated disappointment in each of the imagined rejected-bid and accepted-bid conditions. Anticipated regret $(M=4.94)$ was significantly higher than anticipated disappointment $(M=4.15)$ in the upward pre-counterfactual condition of an accepted bid $(p$ $<.001)$. In contrast, anticipated disappointment $(M=4.33)$ was significantly higher than anticipated regret $(M=$ $3.84)$ in the upward pre-counterfactual condition of a rejected bid $(p<.01)$. Thus, both $\mathrm{H} 3$ and $\mathrm{H} 4$ are supported.

For $\mathrm{H} 5$ and H6, two regression analyses were conducted in order to determine whether the first bidding price was influenced by anticipated regret and anticipated disappointment. As a dummy variable (male $=0$, female $=$ 1), gender was also included in the analyses to control for possible gender influences on the first bidding price. Deciding the amount of a bid is a risk-involved decision, and the literature suggests that women are more risk-averse than men (Jianakoplos \& Bernasek, 1998).

The first regression analysis included anticipated regret and gender as independent variables and first bidding price as a dependent variable. Anticipated regret $(\beta=-.19, r=.25, t(88)=-1.81, p=.074)$ and gender $(\beta=.19, r$ $=.25, t(88)=1.81, p=.075)$ were marginally significant. It appears that people bid lower in order to minimize the regret they might experience in response to the upward counterfactual thought regarding an accepted bid. We also found that gender influenced the first bidding price, as women bid higher than men.

The second regression analysis was run to test the effects of anticipated disappointment and gender as independent variables on first bidding price as a dependent variable. The first bidding price was not predicted by anticipated disappointment $(p>.1)$; thus, hypothesis 6 was not supported. However, the effect of gender was significant $(\beta=.26, r=.27, t(81)=2.43, p=.017)$.

$\mathrm{H} 7$ tests the relative significance of the influence of the anticipated emotions (i.e., regret and disappointment) on the first bidding price. This hypothesis was supported, since the anticipated regret had a significant influence on the first bid and the anticipated disappointment did not, as reported earlier in testing H5 and H6.

In addition to the findings of the effects of upward pre-counterfactual thinking and negative anticipated emotions on the first bidding price, Study 2 also confirmed the findings of Study 1. After the participants in the imagined accepted-bid condition submitted their bid, they were told that their bid was rejected; whereas the participants in the imagined rejected-bid condition were told that their bid was accepted after submitting their bid. The 
participants in each condition were asked to indicate the type of counterfactual thinking. In the rejected-bid condition, upward counterfactual thinking was chosen more $(66 \%)$ than downward counterfactual thinking (34\%), $\chi^{2}(1, N=88)=8.909, p=.003$. In the accepted- bid condition, upward counterfactual thinking was also chosen more (64\%) than downward counterfactual thinking $(36 \%), \chi^{2}(1, N=85)=5.902, p=.015$. The results indicate that bidders engage in upward counterfactual thinking more often than downward counterfactual thinking both when the actual bidding outcome is rejected and when it is accepted, which is consistent with the findings of Study 1. It was also found that there is no difference in upward counterfactual thinking between an accepted bid and a rejected bid $(\mathrm{p}=.567)$.

\section{General Discussion}

Because outcome uncertainty creates some excitement in deciding prices, more consumers are willing to use NYOP auctions for good deals on the Internet. Economic theory suggests that bidding is a risk-taking behavior because the quality and value of the product being auctioned and the price that must be offered to win the auction are uncertain (Vishwanath, 2003). In order to deal with such a high level of uncertainty, bidders tend to mentally simulate the possible positive and negative outcomes (Kahneman \& Tversky, 1982). Our research demonstrates that this high level of uncertainty with limited product information influences bidding amounts through pre-counterfactual thinking and anticipated emotions. In this section, we review the findings and discuss the theoretical and practical implications.

\subsection{Theoretical Contributions}

The findings of study 1 demonstrate that both an accepted bid and a rejected bid generate counterfactual thoughts. This suggests that bidders tend to imagine how bidding outcomes might have turned out if something had been different. Specifically, more upward counterfactual thinking rather than downward counterfactual thinking is elicited in both conditions of an accepted and a rejected bid. For example, bidders tend to think "I wish my bid had been accepted" when their first bid is rejected, whereas the thought "If I had bid lower, I might have saved more" is likely to occur when the first bid is accepted. Although this contradicts the study by Roese and Olson (1997) that suggests that negative outcomes elicit more upward counterfactual thinking than positive or neutral outcomes, it supports Galinsky et al. (2002) proposing that when accepted bids are highly unexpected, this could also result in upward counterfactual thinking about the possibility of over-bidding. More importantly, counterfactual thinking that a bidding outcome could have been better whether the bid is accepted or rejected is equally significant.

Given that there was no difference in upward counterfactual thinking between an accepted and a rejected bid, it appears that both an accepted bid and a rejected bid are perceived as negative outcomes. Why do bidders perceive the acceptance of a first bid as a negative outcome rather than a positive one? According to Lightner et al. (2002), an NYOP auction is a type of auction that incorporates price negotiation between sellers and buyers even though it is not a real-time and interactive exchange that takes place in traditional market places. An immediate acceptance of the first bid, which is a positive outcome, can be evaluated negatively when compared to a possible agreement resulting from a back-and-forth negotiation. This is because bidders can be less satisfied with their obtained positive outcome by imagining an even better outcome (i.e., upward counterfactual thinking) (Galinsky et al., 2002). Thus, it appears that bidders do not enjoy the winning bids that are accepted immediately. This counterintuitive finding may also be consistent with the phenomenon of doing objectively better but feeling subjectively worse (e.g., silver medalists are less satisfied and feel less happy than bronze medalists) (Medvec et al., 1995; Medvec \& Savitsky, 1997).

Study 2 demonstrated that the use of simulation heuristics helps bidders make their bidding decisions. That is, the mental simulation of an accepted bid and a rejected bid will influence the first bidding price through upward pre-counterfactuals and anticipated emotions, regret, and disappointment. Based on Zeelenberg et al. (1998b), we proposed that the upward counterfactual thinking elicited from an accepted bid is behavior-focused while the upward counterfactual thinking elicited from a rejected bid is situation-focused. The findings support our contention that regret was more likely elicited from the behavior-focused counterfactuals and disappointment was more likely evoked from the situation-focused counterfactuals. These two emotions of anticipated regret and anticipated disappointment do not impact the first bidding price evenly.

In Study 1, we found that both accepted and rejected bids elicit upward counterfactual thinking; however, the findings in Study 2 indicate that upward pre-counterfactual thinking from an accepted bid influences the first bidding price more significantly than upward pre-counterfactual thinking from a rejected bid. We suspect that the greater influence of anticipated regret on the amount of a bid is related to the distinctive characteristic of NYOP auctions in which an opportunity to bid again is possible only when the bid is rejected. It appears that 
imagining an accepted bid that cannot be cancelled or changed decreases the first bidding price, thereby minimizing the chances of experiencing the regret associated with the possibility of overbidding. This impact of anticipated regret on first bidding price is attributed to an interesting psychological mechanism of emotion regulation (Zeelenberg, 1999; Zeelenberg \& Pieters, 2007). However, the effect of emotion regulation was not supported for the effect of anticipated disappointment from an imagined rejection of the first bid. We speculate that this lack of support resulted from the second chance available to bid after the rejection. Another explanation of the larger impact of anticipated regret on the first bidding price is "winner regret," which suggests that winners feel regret because they paid more than the second highest bid (Engelbrecht-Wiggans \& Katok, 2009). This overbidding decreases the average bid when winner regret is emphasized. Even though counterfactual thinking appears to be a coping strategy that bidders may employ to deal with the uncertainty of bidding outcomes, what is important is the consequent emotion affecting bidding decisions. This is consistent with the suggestion in the literature that emotional states produced by mental simulations serve as motivations of the subsequent behaviors (Taylor \& Schneider, 1989).

\subsection{Managerial Implications}

The findings of our two studies provide critical implications for the marketing practice of the NYOP auction. From the consumer's perspective, an immediately accepted bid is the positive outcome that bidders wish for. However, our findings suggest that due to counterfactual thoughts, bidders may experience regret for not having bid lower even when they imagine their first bid being accepted; consequently, they may place a lower bid. Marketing managers would not wish their bidders to place lower bids because this is detrimental to their business. Thus, it is essential for marketers to reduce bidders' anticipation of regret from an accepted bid. For example, a more proactive strategy can help reduce consumers' concern with overbidding and emphasize other values of bidding through the NYOP system such as convenience and time savings. In addition, given that bidders have a second chance to bid when the bid is rejected, we find that bidders' first bidding price will not be influenced by anticipated disappointment of an imagined rejected bid. However, this phenomenon may not occur for last-minute bidders. It is possible that last-minute bidders are more likely to feel disappointed that they lose the bid and consequently increase their bidding price. Thus, marketers may emphasize the possibility that the bid may be rejected and provide a suggested bidding price as a reference, particularly for last-minute bidders.

\subsection{Limitations and Future Research}

It is important to note two limitations of our research. The first limitation concerns the measure of regret and disappointment (Marcatto \& Ferrante, 2008) that we used. To the best of our knowledge, few valid measures existed before the one developed by Marcatto and Ferrante (2008). Since their measure has not been adequately replicated and we experienced a marginal reliability, we suggest that the measure should be tested to a greater extent, and that more effort should be invested in refining the measure. The other limitation is how counterfactual thinking was manipulated in our studies, which can be different in actual bidding situations. Future research should test the effect of the counterfactuals that are more naturally elicited. In addition, although our findings revealed that upward counterfactual thinking is more prevalent than downward counterfactual thinking, it is possible that downward counterfactuals that lead to positive emotions can play a different role in consumer decision making. Thus, future research could address how anticipated positive emotions influence consumers' bidding prices.

\section{Acknowledgment}

This paper was completed with Ajou University research fellowship of the year 2014.

\section{References}

Baumgartner, H., Pieters, R., \& Bagozzi, R. P. (2008). Future-oriented emotions: Conceptualization and behavioral effects. European Journal of Social Psychology, 38(4), 685-696. http://dx.doi.org/10.1002/ejsp.467

Bell, D. E. (1985). Disappointment in decision making under uncertainty. Operations Research, 33(1), 1-27. http://dx.doi.org/10.1287/opre.33.1.1

Boninger, D. S., Gleicher, F., \& Strathman, A. (1994). Counterfactual thinking: From what might have been to what may be. Journal of Personality and Social Psyschology, 67(2), 297-307. http://dx.doi.org/10.1037/0022-3514.67.2.297

Chernev, A. (2003). Reverse pricing and online price elicitation strategies in consumer choice. Journal of Consumer Psychology, 13(1\&2), 51-62. http://dx.doi.org/10.1207/S15327663JCP13-1\&2_05 
Cortina, J. M. (1993). What is coefficient alpha? An examination of theory and applications. Journal of Applied Psychology, 78(1), 98-104. http://dx.doi.org/10.1037/0021-9010.78.1.98

Engelbrecht-Wiggans, R., \& Katok, E. (2009). A direct test of risk aversion and regret in first price sealed-bid auctions. Decision Analysis, 6(2), 75-86. http://dx.doi.org/10.1287/deca.1090.0135

Galinsky, A. D., Seiden, V.L., Kim, P. H., \& Medvec, V. H. (2002). The dissatisfaction of having your first offer accepted: The role of counterfactual thinking in negotiations. Personality and Social Psychology Bulletin, 28(2), 271-283. http://dx.doi.org/10.1177/0146167202282012

Gleicher, F., Boninger, D. S., Strathman, A., Armor, D., Hetts, J., \& Ahn, M. (1995). With an eye toward the future: The impact of counterfactual thinking on affect, attitudes, and behavior. In N. J. Roese \& J. M. Olson, (Eds.), What Might Have Been: The Social Psychology of Counterfactual Thinking (pp. 283-304). Mahwah, NJ: Lawrence Erlbaum.

Gleicher, F., Kost, K. A., Baker, S. M., Strathman, A. J., Richman, S. A., \& Sherman, S. J. (1990). The role of counterfactual thinking in judgments of affect. Personality and Social Psychology Bulletin, 16(2), 284-295. http://dx.doi.org/10.1177/0146167290162009

Hetts, J. J., Boninger, D. S., Armor, D. A., Gleicher, F., \& Nathanson, A. (2000). The influence of anticipated counterfactual regret on behavior. Psychology \& Marketing, 17(4), 345-368. http://dx.doi.org/10.1002/(SICI)1520-6793(200004)17:4<345::AID-MAR5>3.0.CO;2-M

Inman, J. J., Dyer, J. S., \& Jia, J. (1997). A generalized utility model of disappointment and regret effects on post-choice valuation. Marketing Science, 16(2), 97-111. http://dx.doi.org/10.1287/mksc.16.2.97

Jianakoplos, N. A., \& Bernasek, A. (1998). Are women more risk averse? Economic Inquiry, 36(4), 620-630. http://dx.doi.org/10.1111/j.1465-7295.1998.tb01740.x

Jones, J. L., Kuan, K. K. Y., \& Newton, S. K. (2000). I name my price but don't want the prize: Effects of seemingly useful information in the name-your-own-price mechanism. Journal of Electronic Commerce Research, 7(4), 178-198.

Kahneman, D., \& Miller, D. T. (1986). Norm theory: Comparing reality to its alternatives. Psychological Review, 93(2), 136-153. http://dx.doi.org/10.1037/0033-295X.93.2.136

Kahneman, D., \& Tversky, A. (1979). Prospect theory: An analysis of decision under risk. Econometrica, 47(2), 263-292. http://dx.doi.org/10.2307/1914185

Kahneman, D., \& Tversky, A. (1982). The simulation heuristic. In D. Kahneman, P. Slovic, \& A. Tversky (Eds.), Judgment under Uncertainty: Heuristics and Biases (pp. 201-208). New York: Cambridge Univ. Press.

Kahneman, D., Knetsch, J. L., \& Thaler, R. H. (1991) Anomalies: The endowment effect, loss aversion, and status quo bias. Journal of Economic Perspectives, 5(1), 193-206. http://dx.doi.org/10.1257/jep.5.1.193

Lightner, N. J., Yenisey, M. M., Ozok, A. A., \& Salvendy, G. (2002). Shopping behavior and preferences in e-commerce of Turkish and American university students: Implications from cross-cultural design. Behavior and Information Technology, 21(6), 373-385. http://dx.doi.org/10.1080/0144929021000071316

Marcatto, F., \& Ferrante, D. (2008). The regret and disappointment scale: An instrument for assessing regret and disappointment in decision making. Judgment and Decision Making, 3(1), 87-99.

Markman, K. D., Gavanski, I., Sherman, S. J., \& McMullen, M. N. (1993). The mental simulation of better and worse possible worlds. Journal of Experimental Social Psychology, 29(1), 87-109. http://dx.doi.org/10.1006/jesp.1993.1005

Markman, K. D., Gavanski, I., Sherman, S. J., \& McMullen, M. N. (1995). The impact of perceived control on the imagination of better and worse possible worlds. Personality and Social Psychology Bulletin, 21(6), 588-595. http://dx.doi.org/10.1177/0146167295216005

McConnell, A. R., Niedermeier, K. E., Leibold, J. M., El-Alayli, A. G., Chin, P. P., \& Kuiper, N. M. (2000). What if I find it cheaper someplace else?: Role of prefactual thinking and anticipated regret in consumer $\begin{array}{lllll}\text { behavior. Psychology } \quad \& \quad \text { Marketing, } & \text { 17(4), }\end{array}$ http://dx.doi.org/10.1002/(SICI)1520-6793(200004)17:4<281::AID-MAR2>3.0.CO;2-5

Medvec, V. H., \& Savitsky, K. (1997). When doing better means feeling worse: The effects of categorical cutoff points on counterfactual thinking and satisfaction. Journal of Personality and Social Psychology, 72(6), 1284-1296. http://dx.doi.org/10.1037/0022-3514.72.6.1284 
Medvec, V. H., Madey, S. F., \& Gilovich, T. (1995). When less is more: Counterfactual thinking and satisfaction among olympic medalists. Journal of Personality and Social Psychology, 69(4), 603-610. http://dx.doi.org/10.1037/0022-3514.69.4.603

Miller, D. T., \& Taylor, B. R. (1995). Counterfactual thought, regret, and superstition: How to avoid kicking yourself. In N. J. Roese, \& J. M. Olson (Eds.), What Might Have Been: The Social Psychology of Counterfactual Thinking (pp. 305-331). Mahwah, NJ: Erlbaum.

Roese, N. J. (1994). The functional basis of counterfactual thinking. Journal of Personality and Social Psychology, 66(5), 805-818. http://dx.doi.org/10.1037/0022-3514.66.5.805

Roese, N. J. (1997). Counterfactual thinking. Psychological Bulletin, 121(1), 133-148. http://dx.doi.org/10.1037/0033-2909.121.1.133

Roese, N. J., \& Hur, T. (1997). Affective determinants of counterfactual thinking. Social Cognition, 15(4), 274-290. http://dx.doi.org/10.1521/soco.1997.15.4.274

Roese, N. J., \& Olson J. M. (1997). Counterfactual thinking: The intersection of affect and function. Advances in Experimental Social Psychology, 29, 1-59. http://dx.doi.org/10.1016/S0065-2601(08)60015-5

Sanna, L. J. (1996). Defensive pessimism, optimism, and simulating alternatives: Some ups and downs of prefactual and counterfactual thinking. Journal of Personality and Social Psychology, 71(5), 1020-1036. http://dx.doi.org/10.1037/0022-3514.71.5.1020

Sanna, L. J., Turley. K. J. (1996). Antecedents to spontaneous counterfactual thinking: Effects of expectancy violation and outcome valence. Personality and Social Psychology Bulletin, 22(9), 906-919. http://dx.doi.org/10.1177/0146167296229005

Shapiro, D., Zillante, A. (2009). Naming your own price mechanisms: Revenue gain or drain? Journal of Economic Behavior \& Organization, 72(2), 725-737. http://dx.doi.org/10.2139/ssrn.1260854

Tassabehji, R., Taylor, W. A., Beach, R., \& Wood, A. (2006). Reverse e-auctions and supplier-buyer relationships: an exploratory study. International Journal of Operation \& Production Management, 26(2), 166-184. http://dx.doi.org/10.1108/01443570610641657

Taylor, S. E., \& Schneider, S. K. (1989). Coping and the simulation of events. Social Cognition 7(2), 174-194. http://dx.doi.org/10.1521/soco.1989.7.2.174

Van Dijk, E., \& Zeelenberg, M. (2005). On the psychology of 'if only': Regret and the comparison between factual and counterfactual outcomes. Organizational Behavior and Human Decision Processes, 97(2), 152-160. http://dx.doi.org/10.1016/j.obhdp.2005.04.001

Vishwanath, A. (2003). Comparing online information effects: A cross-cultural comparison of online information and uncertainty avoidance. Communication Research, 30(6), 579-598. http://dx.doi.org/10.1177/0093650203257838

Zeelenberg M., van Dijk W. W., Manstead, A. S. R., \& van der Pligt, J. (1998a). The experience of regret and disappointment. Cognition and Emotion, 12(2), 221-230. http://dx.doi.org/10.1080/026999398379727

Zeelenberg, M. (1999). Anticipated regret, expected feedback and behavioral decision making. Journal of Behavioral Decision Making, 12(2), 93-106. http://dx.doi.org/10.1002/(SICI)1099-0771(199906)12:2<93::AID-BDM311>3.0.CO;2-S

Zeelenberg, M., \& Pieters, R. (1999). Comparing service delivery to what might have been: Behavioral responses to regret and disappointment. Journal of Service Research, 2(1), 86-97. http://dx.doi.org/10.1177/109467059921007

Zeelenberg, M., \& Pieters, R. (2007). A theory of regret regulation 1.0. Journal of Consumer Psychology, 17(1), 3-18. http://dx.doi.org/10.1207/s15327663jcp1701_3

Zeelenberg, M., Van Dijk, W. W., Manstead, A. S. R., \& Van der Pligt, J. (2000). On bad decisions and disconfirmed expectancies: The psychology of regret and disappointment. Cognition and Emotion, 14(4), 521-541. http://dx.doi.org/10.1080/026999300402781

Zeelenberg, M., van Dijk, W. W., van der Pligt, J., Manstead, A. S. R., van Empelen, P., \& Reinderman, D. (1998b). Emotional reactions to the outcomes of decisions: The role of counterfactual thought in the experience of regret and disappointment. Organizational Behavior and Human Decision Resources, 75(2), 117-141. http://dx.doi.org/10.1006/obhd.1998.2784 


\section{Copyrights}

Copyright for this article is retained by the author(s), with first publication rights granted to the journal.

This is an open-access article distributed under the terms and conditions of the Creative Commons Attribution license (http://creativecommons.org/licenses/by/3.0/). 